\title{
Methodological and computer-based support for choosing underground utility networks renovation method
}

\author{
Dmitriy Goncharenko, Ihor Shumakov, Olha Starkova*, Alevtyna Aleinikova, and Revaz \\ Mikautadze ${ }^{1}$ \\ Kharkiv National University of Civil Engineering and Architecture, Sumska st. 40, 61002 Kharkiv, \\ Ukraine
}

\begin{abstract}
The article is devoted to the methodological and software tools for choosing organizational and technological solutions to maintain sewage collectors in an operable state to increase their service life. Such a tool must take into account a set of factors that affect the operation of sewer collectors and form a system, the implementation of which would improve the existing principles of monitoring the status of sewer collectors, identify effective organization and technological solutions of their renovation by taking into account factors that affect their safe operation, the facilities risk of accidents categories, conditions and parameters of works performance. For determining the optimal options for the renovation of the sewer collector using the developed mathematical and computer models, the results of problems solving were generalized: one-criterion optimization subject to the choice of one repair method; one-criterion optimization subject to the choice of different repair methods for the areas; multicriterion optimization.
\end{abstract}

\section{Introduction}

The sewage system of any human settlement is one of the most expensive and vulnerable parts of underground engineering infrastructure. The environment, the comfort of the population, and the efficient work of the city enterprises depend on its reliable and uninterrupted work $[1,2]$.

At the moment there is practically no planned approach in preparing a complex of organizational and technological solutions that would increase the service life of sewer collectors. In addition, such networks that are hidden underground, require attention only when there are emergency situations, and the complex of solutions for the support of these systems is reduced to emergency repair works at the collector site in order to eliminate the consequences of the accident [3-5]. This approach to the works management leads to a high cost of all types of utilities resources and, consequently, to adverse economic, environmental and social effects.

\footnotetext{
* Corresponding author: starkova.olha@gmail.com
} 
Recent trends have shown that closed (trenchless) technologies have been used ever more commonly for the repair and renovation of sewage pipelines associated with the replacement of reinforced concrete, cast iron and other types of tubes with modern materials in the utilities of the European cities [4-13]. However, in contemporary practice of sewage pipeline repair there is no clear mechanism for selecting effective trenchless methods of underground communications repair.

In view of the above, developing methodological and software tools for choosing organizational and technological solutions is required to maintain sewage collectors in an operable state, which will increase their service life. Such a tool must take into account a set of factors that affect the operation of sewer collectors and form a system, the implementation of which would improve the existing principles of monitoring the status of sewer collectors, identify effective organization and technological solutions of their renovation by taking into account factors that affect their safe operation, the facilities risk of accidents categories, conditions and parameters of works performance [14].

\section{Materials and methods}

Today there are more than 20 contemporary trenchless methods of restoring water supply networks and sewage system of different diameters, with their advantages and disadvantages, each of them being unique and requiring justification for the effective use a particular method in accordance with the operational, structural and technical characteristics of the networks. Features of organizational and technological solutions do not allow to trace the direct connection between the choice of each particular method based on the degree of damage to the network area (its categorization). In addition, it is difficult to estimate the cost equivalent of each of the methods and choose a more acceptable method based, for instance, on cost parameters.

To solve this problem, a system has been proposed that allows to reasonably choose a restoration method or repair of a sewer collector focusing on most parameters of its operation, and also taking into account the features of organizational and technological repair solutions (fig. 1).

\section{Results}

To implement each of the steps given in fig. 1, the software toolkit has been developed. For example, in order to determine the categorization of sewer network areas, an expert system was implemented as a system of fuzzy logic output in a trial version of the MATLAB system using the Fuzzy Logic Toolbox, which contains a set of GUI modules providing the implementation structural identification stage in a dialog mode.

The connection between the input and output variables is carried out using the knowledge base. It contains over 200 rules that take into account all the combinations of input variables and the effect of these combinations on the categorization of the sewer collector area.

One of the results of the system based on the set values of input variables is presented in fig. 2. Thus, with a reduction of the cross section to $50 \%$, the presence of cracks (their opening width) having size of $10 \mathrm{~mm}$, deformation of about $25 \%$, in the presence of breaks in pipes up to $3 \mathrm{~cm}$, corrosion of reinforced concrete by $50 \%$, pre-treated wastewater and lack the wetlands on the pipeline route, the system assigns the category 2 to an area - a critical condition. 


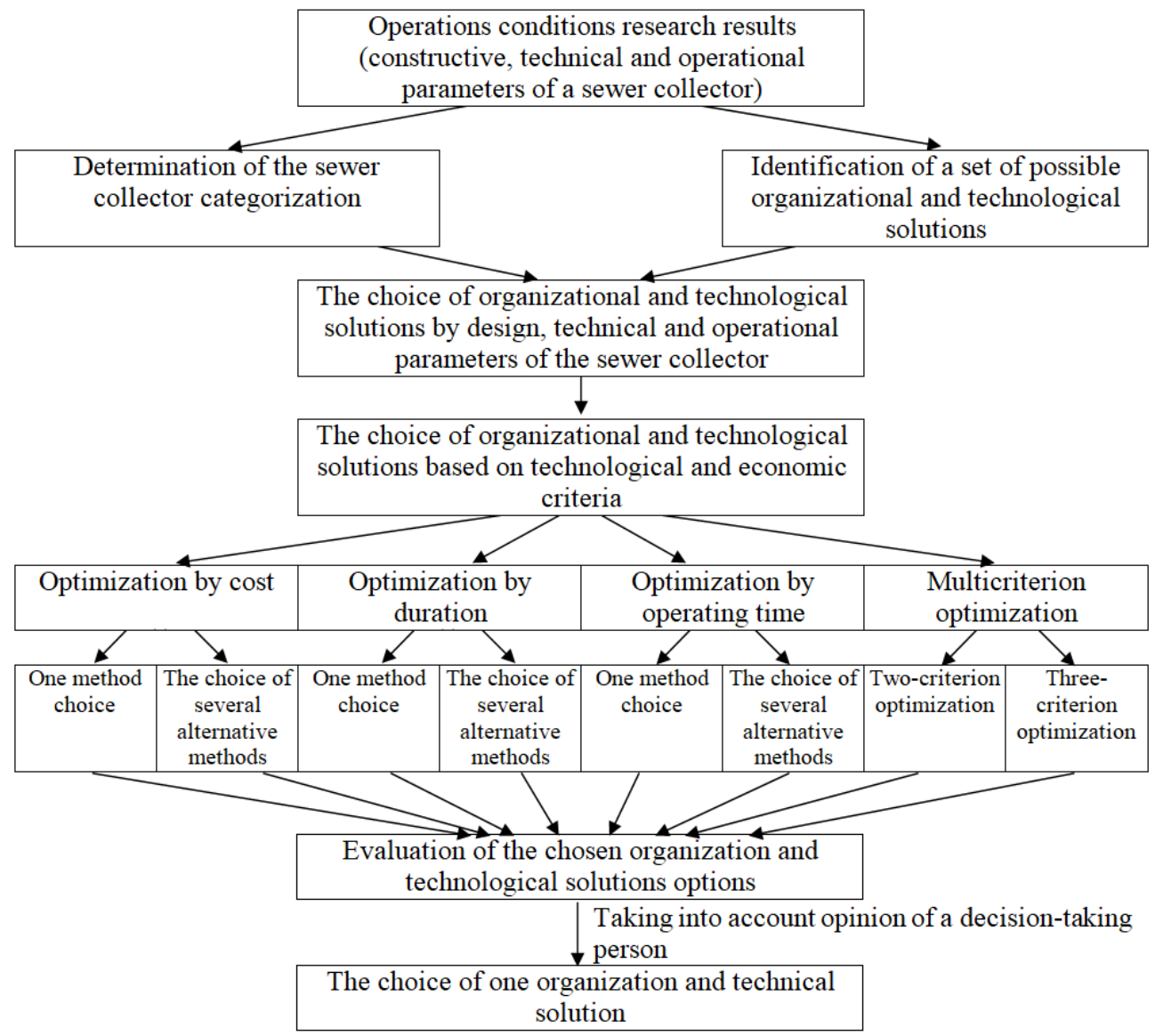

Fig. 1. The system of the solutions complex management for increasing the sewer collector service life.

Rule Viewer: KlassPravial

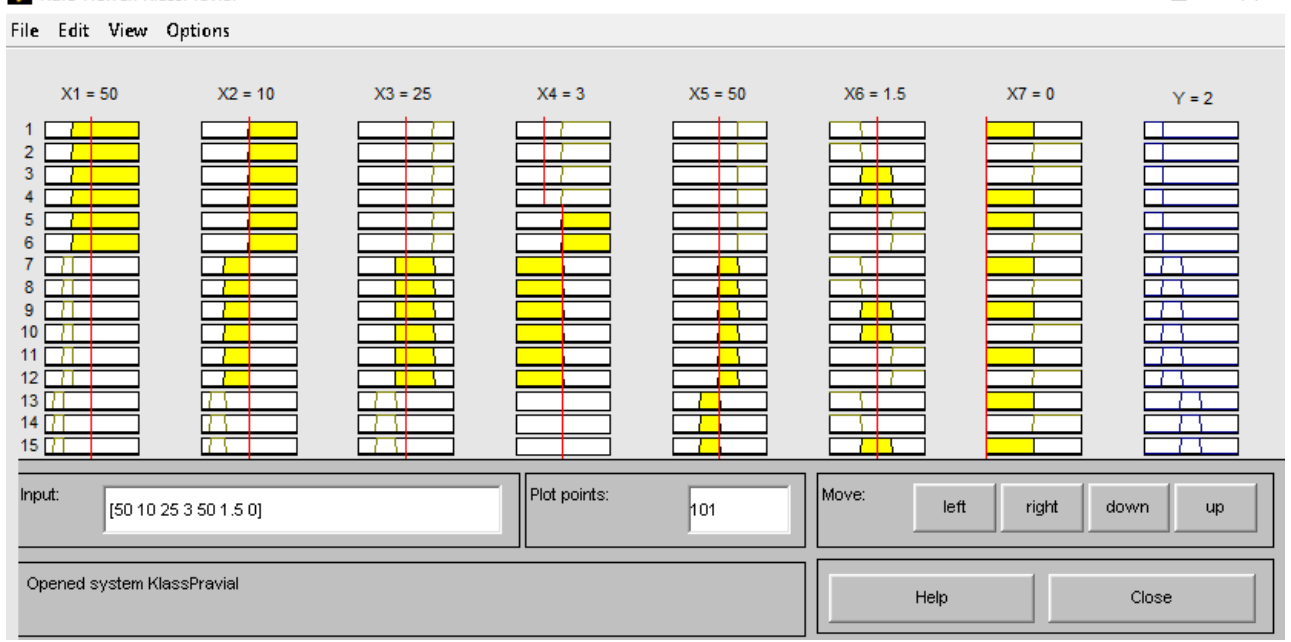

Fig. 2. The result of the system operation based on the set values of input variables. 
A mechanism is developed which, based on the collector area parameters, allows choosing promising methods for its renovation. The solution of such a problem with the use of mathematical modeling is virtually impossible, since the diversity of the parameters of the area and the set of characteristics of each of the repair methods is very difficult to reduce to n-dimensional space of solutions, where $n$ would equal to at least three. In addition, it is advisable to obtain more than one alternative method of repair of the sewer collector to choose from based on the design, technical and operational parameters of the network area. For this purpose, an algorithmic model of the reasoned choice of a repair method and restoration of the sewer collector area is proposed, which takes into account the design, operational and other characteristics of the site. The result of the model operation is a set of repair methods, which are selected taking into account the design, technical and operational parameters of the sewer collector area.

Mathematical models were developed to choose organizational and technological solutions based on technological and economic criteria: one-criterion optimization, subject to the choice of one method of the sewer collector area repair; one-criterion optimization, subject to the choice of several methods of the sewer collector area repair; multicriterion optimization subject to choosing the methods of the sewer collector area repair.

In a situation where the length of the area is insignificant, choosing one method of its renovation is the most expedient. For this purpose, mathematical models of one-criterion optimization were developed, subject to the choice of one method of sewer collector area repair:

$$
\begin{gathered}
\sum_{i=1}^{n} c_{i} \cdot l \cdot x_{i} \rightarrow \min \\
\left\{\begin{array}{l}
x_{i} \in\{0 ; 1\}, \quad i=\overline{1, n} ; \\
\sum_{i=1}^{n_{i}} x_{i}=1 ; \\
c_{i} \in C_{i_{k}}, \quad k=\overline{1, m},
\end{array}\right.
\end{gathered}
$$

(1) - mathematical model in which optimization criterion is the cost of the repair works complex;

$i$ - repair method and renovation number; $i=1, \ldots, n$;

$n$ - the number of repair methods;

$c_{i}$ - the cost of repair works package (including materials and works performance costs) for 1 linear meter of the sewer collector by $i$-method;

$l$ - the length of the repaired area, $\mathrm{m}$;

$x_{i}-$ logical variable reflecting the fact of choice of $i$-repair method:

$$
x_{i}=\left\{\begin{array}{l}
1, \text { in case } i \text {-repair method is chosen, } \\
0, \text { otherwise; }
\end{array}\right.
$$

$C_{i k}-$ cost characteristics of $i$ repair methods set which can be used in the area subject to its structural, technical, and operation $k$ parameters;

$m$ - the number of repair methods set which can be used in the area subject to its structural, technical, and operation $k$ parameters.

Similarly formulated mathematical model in which optimization criterion is the duration of the repair works complex, mathematical model in which optimization criterion is the failure free operating period.

When operating entity has a sufficient time reserve, and the length of area is significant, or it is necessary to carry out the repair of a herring-bone pattern of sewer mains with tie- 
ins, the choice of different renovation methods is expedient. For this purpose, mathematical models of one-criterion optimization were developed, subject to the choice of several methods of sewer collector area repair:

$$
\begin{gathered}
\sum_{i=1}^{n} \sum_{j=1}^{m} c_{i j} \cdot l_{j} \cdot x_{i j} \rightarrow \min \\
\left\{\begin{array}{l}
x_{i j} \in\{0 ; 1\}, \quad i=\overline{1, n}, \quad j=\overline{1, m} ; \\
\sum_{j=1}^{n_{i}} x_{i j}=1, \quad i=\overline{1, n} ; \\
c_{i j} \in C_{i j_{k}}, \quad k=\overline{1, p}
\end{array}\right.
\end{gathered}
$$

(2) - mathematical model in which optimization criterion is the cost of the repair works package;

$i$ - repair method and renovation number; $i=1, \ldots, n$;

$n$ - the number of repair methods;

$j$ - the number of sewer collector area; $j=1, \ldots, m$;

$m-$ the number of sewer collector areas that are subject to repair;

$c_{i j}$ - the cost of repair works package (including materials and works performance costs) for 1 linear meter of the $j$ sewer collector area by $i$-method;

$l_{j}$ - the length of the repaired $j$ area, $\mathrm{m}$;

$x_{i j}$ - logical variable reflecting the fact of choice of $i$-repair method for $j$ area:

$$
x_{i j}=\left\{\begin{array}{l}
1, \text { in case } i \text {-repair method for } j \text { area is chosen, } \\
0, \text { in the opposite case; }
\end{array}\right.
$$

$C_{i k}-$ cost characteristics of $i$ repair methods set which can be used in the $j$ area subject to its structural, technical, and operation $k$ parameters;

$p$ - the number of repair methods set which can be used in the area subject to its structural, technical, and operation parameters.

Similarly formulated mathematical model in which optimization criterion is the cost of the repair works package and mathematical model in which optimization criterion is the failure free operating period.

Besides, mathematical models of multicriterion optimization for solving the problem of choosing the method of the sewer collector area repair were developed.

With the use of modern specialized and standard computer technologies a software toolkit was developed for implementation of the mechanism for justified choice of the sewer collector area repair method and renovation.

The developed methodological principles of the choice and software tools were tested on the collector damaged section, which passes along the street Volohaevskaya (Kharkiv). This area includes seven pools. After a detailed study of the data on the areas technical condition and the definition of their categorization, the appropriate information is entered in the dialog box, based on which rational renovation methods are chosen for each individual case. The working area for introducing of the sewer collector area input parameters by the user and the result of an automated selection of promising repair methods on the basis of input data set by the user is provided in fig. 3. Here, the contrasting color automatically highlights those methods that can be applied based on the structural, technical and operational parameters of the area.

In order to analyze the optimal options for the renovation of the sewer collector using the developed mathematical and computer models, the results of problems solving were generalized: 
- one-criterion optimization subject to the choice of one repair method;

- one-criterion optimization subject to the choice of different repair methods for the areas;

- multicriterion optimization.

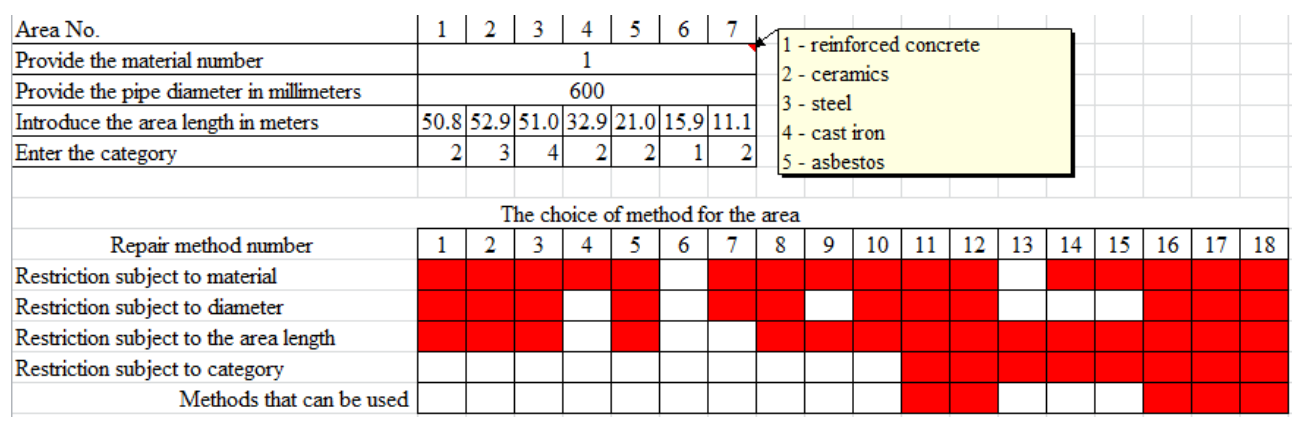

Fig. 3. Working area for introducing by the user input parameters of sewer collector area and automated selection of repair methods for the sewer collector area.

\section{Conclusions}

Thus, the introduction of methodological principles and software tools for choosing organizational and technological solutions to extend the service life of utility networks allows improvement of the efficiency of the decision-making process in identifying alternative methods of repair and renovation which is a reasoned argument in the context of insufficient financing of the plumbing and sewer industry.

\section{References}

1. A.I. Aleynikova, V.M. Volkov, D.F. Goncharenko, G.G. Zubko, O.V. Starkova. Rarities of Ukraine, Methodological basis for underground utility networks service life extension: monograph: under the general editorship of Starkova O.V., 320 (2017)

2. A. Garmash, D. Bondarenko, G. Zubko, D. Goncharenko. World Journal of Engineering, On renovation of the destroyed tunnel sewer collector in Kharkiv, E 13, 72 (2016)

3. D. Bondarenko, V. Bulhakov, A. Garmash, D. Goncharenko, S. Pilihram. Rarytety Ukrainy, Sewage tunnels of Kharkiv: QUO VADIS: monograph: under the general editorship of D.F. Honcharenko, 232 (2018)

4. I.A. Abramovich. Globus, Wastewater Networks and Facilities. Calculations, Designing, Operation, 288 (2005)

5. V.A. Orlov, V.A. Kharkin. ROST, Development of a Strategy for Reconstructing Urban Drainage Networks, E 3, 20 (2001)

6. D. Stein. Ernst und Sohn, Instandhaltung von Kanalisationen, 941 (1999)

7. R. Stein, Sh. Ghaderi. Stein \& Partner, Wertemittung von Abwassernetzen, 131 (2010)

8. K. Ochs. Bi UmweltBau, Die Wahl einer Gesamtsanierungsstrategie, E 5, 19 (2013)

9. K. Körkemeyer, M. Schmitz. BauPortal ,Werkstoffauswahl für Rohre und Schächte der Kanalisation, E 7, 22 (2014) 
10. K. Körkemeyer, S. Kapitel. Springer-Verlag, Zementgebundene Werkstoffe (Beton, Stahlbeton, Spannbeton), im Fachbuch ,Rohrleitungen“, E 1, 25 (2015)

11. K. Körkemeyer. Betonwerk- und Fertigteiltechnik, State-of-the-art sewer construction using precast elements, E 2, 59 (2015)

12. J. Kölbe. Wasser-Abwasser, Benchmarking des Prozesser Wasserlustmanagement in Trinkwasserversorgungsystemen, E 1, 68 (2010)

13. O. Gutierre, J. Mohanakrishnan, K. Sharma, R. Meyer, J. Keller, Z. Yuan. Water Research, Evaluation of oxygen injection as a means of controlling sulfide production in a sewer system, E 42, 17 (2010)

14. O.V. Starkova. KNUSEA, System of scientifically grounded choice of organizational and technological solutions that provide increase in service life of sewer collectors: Thesis of a Dr.Sci.Tech, 332 (2017) 